\title{
La fabricación del enemigo: los indios pijaos en el Nuevo Reino de Granada, 1562-1611
}

Resumen: Este artículo analiza la imagen negativa que los conquistadores españoles construyeron sobre los indios pijaos con el fin de legitimar su conquista y su posterior incorporación al sistema colonial. Los españoles inventaron o resaltaron varias de las características de estos indios: antropofagia, dispersión de los asentamientos, guerras interétnicas, desnudez, pobreza, debilidad de los caciques, entre otros. A partir de la segunda mitad del siglo XVI, las autoridades coloniales permitieron que se organizaran verdaderas campañas de guerra a "sangre y fuego" que facilitaron la conquista atroz y brutal de las diferentes naciones indígenas que habitaban en una zona fronteriza compartida por el Nuevo Reino de Granada y Popayán.

Palabras clave: pijaos, frontera, naciones, guerra, clasificaciones étnicas.

\section{Making the enemy: the Pijao Indians in the New Kingdom of Granada, 1562-1611}

Abstract: This article analyzes the negative image of the Pijao Indians that Spanish conquerors built to legitimize their conquest and their subsequent incorporation into the colonial system. The Spanish invented or highlighted several of the characteristics of these Indians: anthropophagy, dispersal of settlements, inter-ethnic wars, nudity, poverty, weakness of the chiefs, among others. Since the second half of the 16th century, the colonial authorities allowed actual "blood and fire" war campaigns that facilitated the atrocious and brutal conquest of the different indigenous nations that inhabited a region border area shared by the New Kingdom of Granada and Popayan.

Keywords: pijaos, borderland, nations, war, ethnic classifications.

\section{A fabricação do inimigo: os índios Pijao no Novo Reino de Granada, 1562-1611}

Resumo: Este artigo analisa a imagem negativa que os conquistadores espanhóis construíram dos índios Pijao para legitimar sua conquista e sua posterior incorporação ao sistema colonial. Os espanhóis inventaram ou destacaram várias das características desses índios: antropofagia, dispersão de assentamentos, guerras interétnicas, nudez, pobreza, fraqueza dos chefes, entre outros aspectos. A partir da segunda metade do século XVI as autoridades coloniais permitiram que se organizassem verdadeiras campanhas de guerra a "sangue e fogo" que facilitaram a conquista atroz e brutal das diferentes nações indígenas que viviam em uma área de fronteira compartilhada pelo Novo Reino de Granada e Popayán. Palavras-chave: pijaos, fronteira, nações, guerra, classificações étnicas.

Cómo citar este artículo: Juan David Montoya Guzmán, "La fabricación del enemigo: los indios pijaos en el Nuevo Reino de Granada, 1562-1611”, Trashumante. Revista Americana de Historia Social 19 [2022]: 96-117.

DOI: 10.17533/udea.trahs.n19a05

Fecha de recepción: 22 de marzo de 2021

Fecha de aprobación: 26 de agosto de 2021

Juan David Montoya Guzmán: Doctor en Historia de América por la Universidad Pablo de Olavide. Profesor asociado de la Universidad Nacional de Colombia, sede Medellín. ORCID: 0000-0002-6920-6846. Correo electrónico: jdmonto6@unal.edu.co 


\title{
La fabricación del enemigo: los indios pijaos en el Nuevo Reino de Granada, 1562-1611
}

Juan David Montoya Guzmán

\author{
"Lanza no caigas al suelo \\ Porque vuelven los pijaos".
}

"Devocionario de Ibagué", San Bonifacio de Ibagué del Valle de las Lanzas. Documentos para su historia, dir. Enrique Ortega Ricaurte (Bogotá: Editorial Minerva, 1952) 201.

\section{Introducción}

E1 30 de enero de 1790, el cabildo en pleno de la ciudad de Santiago de Cali se Econgregó para jurar a Carlos IV como nuevo monarca español. Para reforzar la solemnidad de la fiesta, se condujo desde el barrio de La Merced un carruaje iluminado al que acompañaron con música y descargas de escopetas, y que contenía dos retratos del rey y la reina. Para aumentar la suntuosidad de la celebración, se hizo un recorrido por los principales lugares de la ciudad, encabezado por los alcaldes ordinarios y seguido de música y pólvora. A continuación, se ordenó que repicaran las campanas de la iglesia, se adornaron el edificio del ayuntamiento, la casa del alférez real don Manuel de Caicedo y toda la plaza mayor. Hombres y mujeres de diferentes calidades se reunieron en la plaza para escuchar el juramento. Desde un tablado cubierto con damasco carmesí, el alférez juró a Carlos IV lealtad en nombre de todo el vecindario. Durante los ocho días siguientes, se corrieron toros, se presentaron comedias, se bailaron contradanzas, y el último día se realizó un torneo en el que, según las palabras del escribano Manuel de Victoria, se hicieron "castillos portátiles, torres, palacios, azucenas, chozas, hospitales que se tiraban en carretas, multitud de máscaras, ya de monos colorados, serpientes, leones, indios pijaos con flechas, umbitos negros, chicos y grandes, con otra infinidad de ideas". Lo interesante de toda esta descripción es que, todavía en el ocaso del periodo colonial, se seguía representando a los pijaos como los indios bárbaros y belicosos

1. “Jura Carlos IV en Cali", Boletín de Historia y Antigüedades 5 (1909): 159-167. Cursiva del autor. 
por excelencia. ¿Cómo se construyó esta imagen? ¿De qué forma se desarrolló este estereotipo? Estas preguntas se tratarán de resolver a lo largo de este texto.

Así pues, el objetivo de este artículo es analizar la forma como los conquistadores construyeron una serie de representaciones negativas sobre los indios con el fin de legitimar su conquista y su posterior incorporación al sistema colonial. Se analizará el caso de los pijaos, considerados por los ibéricos como los bárbaros por antonomasia, portadores de todos lo adjetivos negativos que se le podían endilgar a los naturales: canibalismo, dispersión, estructura política débil, pobreza o desnudez.

\section{El origen de los pijaos}

En 1591, don Antonio González, presidente de la Audiencia de Santafé, contaba con cierta experiencia en las prácticas de pacificación en las fronteras americanas. Antes de tomar posesión en Santafé de Bogotá, se había desempeñado en la misma función en la Audiencia de Guatemala, de modo que estaba familiarizado con las particulares formas de conquista y poblamiento que imperaban en las regiones remotas de América. Gracias a la lectura de los informes que enviaban gobernadores, obispos, viejos capitanes y encomenderos, conocía el abismo que separaba a los virreinatos novohispanos y peruanos de la inestabilidad que aquejaba las regiones fronterizas. $^{2}$

La agitación que se vivía en Ibagué,Timaná o Cartago le recordaba a González las noticias inquietantes que llegaban al Consejo de Indias sobre el norte de la Nueva España o Chile. En una de esas cartas enviadas al rey, se informaba que los indios pijaos eran "gente áspera y que comen carne humana", además de ser los causantes de "grandes insultos y daños a los españoles y no estar subjetos a cacique ni tener población çierta sino que son como alárabes”. Y luego proponía que se esclavizara a los pijaos como se hacía con los chichimecas, debido a su naturaleza "bárbara". 3

Cuando el término "pijao" se empezó a utilizar ampliamente entre las autoridades del Nuevo Reino de Granada era ya un apelativo que tenía un amplio uso entre los vecinos de Ibagué, Tocaima, Timaná, La Plata, Neiva, Buga y Cartago. Contrario a lo que pasa con muchos nombres de naciones, es posible reconstruir la genealogía de la categoría "pijao" desde su zona de nacimiento hasta su progresiva especialización como "indios de guerra”. Fray Pedro Simón, quien participó en las campañas más violentas contra estos indios en la primera década del siglo XVII, anotó en sus Noticias Historiales que el vocablo pijao era la corrupción de la voz

2. Antonio González fue oidor de la Cancillería de Granada y en 1568 fue nombrado oidor de la Audiencia de Guatemala hasta 1573. Regresó a España a su antiguo cargo y en 1584 fue elegido oidor del Consejo de Indias, para luego ser promovido al Nuevo Reino de Granada como presidente de la Audiencia de Santafé, oficio que desempeñó entre 1589 y 1600. Véase Ernesto Schäfer, El Consejo Real y Supremo de las Indias. Su historia, organización y labor administrativa hasta la terminación de la Casa de Austria, t. 1 (Madrid: Junta de Castilla y León / Marcial Pons, 2003) 338.

3. AGI, Sevilla, Santa Fe, 17, r. 8, 46, f. 7v. 
"pinaes", pues los invasores europeos percibieron a los nativos "tan deshonestos" que, haciendo un juego de palabras para referirse al miembro viril, decidieron cambiar "la $\mathrm{N}$ en la otra letra, con que se ha ido corriendo este vocablo hasta el día de hoy". 4

Los primeros en tener contacto con los pijaos fueron los miembros de las tropas de Sebastián de Belalcázar, quienes recorrieron el valle alto del río Magdalena al finalizar la década de 1530. Los conquistadores notaron que había indios belicosos en la cordillera Central y que defendían su territorio lanzando flechas envenenadas. Pedro de Puelles, uno de los hombres que acompañó a Belalcázar en su expedición, declaró que "hallaron unas laderas de sierras de unos pueblos muy chiquitos y mala gente y pobre y mucha hierba, donde cada día les mataban gente". ${ }^{5}$ El mismo Belalcázar declaró que cuando atravesó el valle de la "Tristura", los soldados se percataron de una división que era fundamental: en toda la región, los naturales peleaban con lanzas y macanas, pero de Neiva hacia el norte los nativos utilizaban "flechas con hierba". La diferencia entre lanzas y macanas, de un lado, y arcos y flechas envenenadas, de otro, era un importante indicio de la capacidad bélica de los indios, así como de su grado de combatividad, lo cual debía tenerse en cuenta para la estrategia militar a seguir. ${ }^{6}$

Años después, los mismos soldados de la tropa de Belalcázar narraron al adelantado Pascual de Andagoya que en la provincia de Apirama los españoles se habían enfrentado a un escuadrón de dos mil combatientes paeces "tan bien hordenado como se podrá hacer en toda Ytalia". Pero lo más interesante es que estos indios tenían grupos de guerreros especializados. Se trataba de "gente a sueldo de otra provincia que con ellos confyna que se dicen los Tyjajos". Por supuesto, se trataba de los pijaos, y, según el testimonio de Andagoya, estos eran mercenarios que luchaban con macanas y eran utilizados como tropas de choque.

Los excesos cometidos durante la primera mitad del siglo XVI en todo el continente americano y las denuncias del bando lascaciano llevaron a que Carlos V ordenara suspender las expediciones militares en 1549, para dar paso a un periodo interregno (1550-1559) en el que la Corona vio cómo los oficiales, los encomenderos y los capitanes suplicaban para que se autorizaran nuevamente las entradas hacia los territorios que aún no se habían conquistado. El permiso para realizar

4. Fray Pedro Simón, Noticias historiales de las conquistas de Tierra Firme en las Indias Occidentales, t. 5, ed. Juan Friede (Bogotá: Biblioteca Banco Popular, 1981) 261.

5. Juan Friede, Documentos inéditos para la historia de Colombia, t. 5 (Bogotá: Academia Colombiana de Historia, 1957) 214.

6. Bernardo Tovar Zambrano, "Conquista española y resistencia indígena. Las provincias de Timaná, Neiva y La Plata durante el siglo XVI", Historia general del Huila, t. 1, eds. Bernardo Tovar Zambrano, Guillermo González Otálora y Gabriel Castro Rouillé (Neiva: Instituto Huilense de Historia / Fondo de Autores Huilenses / Gobernación del Departamento del Huila / Academia Huilense de Historia, 1995) 213-326.

7. "Relación que da el Adelantado de Andaboya de las tierras y probincias que abaxo se ara mencion", Relaciones y visitas a los Andes. S. XVI, t. 1, ed. Hermes Tovar Pinzón (Bogotá: Colcultura / Instituto de Cultura Hispánica, 1993) 180-181. 
nuevas campañas de pacificación en 1559 condujo a una política de conquista a "fuego y sangre", impulsada por la primera bancarrota del reinado de Felipe II en 1557 y la necesidad de metal para sostener la política expansionista de Castilla en el Viejo Mundo. La autorización para hacer nuevas expediciones militares trajo consigo la radicalización del relato sobre los nativos, pues se les trató como inferiores, tildándolos de bárbaros, sodomitas y antropófagos, y a la vez se construyó una imagen ambigua con respecto al territorio, debido a que se consideró a las provincias indígenas como ricas en metales preciosos, pero malsanas y peligrosas para la vida de los hombres europeos.

La denominación "pijao" apareció nuevamente a mediados del siglo XVI con la fundación de la ciudad de Ibagué en 1550. En esos primeros años, a los indios que serían designados con este rótulo los confundieron con otros grupos, como los paeces. ${ }^{8}$ Sin embargo, el fracaso de las expediciones de Francisco de Trejo y Juanes de Gaviria y los ataques de nativos a la villa de La Plata hicieron que los españoles definieran mejor los límites de ambas naciones. ${ }^{9}$ Por ejemplo, en una visita realizada por el licenciado Diego Angulo de Castejón hacia 1560, se anotó que estos dos grupos asaltaban y esclavizaban a los naturales de Neiva y Timaná, y que además eran "caribes". ${ }^{10}$

En 1562, Domingo de Lozano exploró buena parte de la cordillera Central. En su recorrido, esclavizó y asesinó a cientos de pijaos y fundó la ciudad de SanVicente de Páez. Este centro urbano se ubicó en una zona montañosa donde confluían paeces y pijaos. Al referirse a la decidida resistencia de estos últimos, el franciscano Pedro de Aguado los describió en su Recopilación Historial como:

8. Diversas crónicas y documentos redactados a lo largo del siglo XVI testimonian las alianzas que mantuvieron pijaos y paeces. Estos últimos estaban asentados en las cuencas de los ríos Páez, Moras y La Plata, entre el nevado del Huila y el páramo de Guanacas. Aunque era un territorio con una geografía accidentada, su ubicación permitía a los paeces mantener contactos comerciales y alianzas políticas con las naciones que habitaban en ambas vertientes de la cordillera Central, principalmente con los pijaos. Véase Juan Friede, Los Andakí, 1538-1947. Historia de la aculturación de una tribu selvática (México: Fondo de Cultura Económica, 1974) 44-46.

9. Las naciones indígenas, más aún en zonas marginales del imperio hispánico, no se parecían en nada a los grandes grupos que encontraron los invasores europeos en la Nueva España o el Perú. En términos generales, las numerosas naciones que habitaban, por ejemplo, en las fronteras del Nuevo Reino de Granada nunca pudieron afirmarse o siquiera reivindicarse como tales, sencillamente por su definición y porque su delimitación no era obra suya, sino de los invasores europeos o sus aliados nativos. Chantal Cramaussel ha analizado este proceso para el norte novohispano. Véase Chantal Cramaussel, "De cómo los españoles clasificaban a los indios: naciones y encomiendas en la Nueva Vizcaya central", Nómadas y sedentarios en el norte de México. Homenaje a Beatriz Braniff, eds. Marie-Arite Hers y otros (México: Universidad Nacional Autónoma de México, Instituto de Investigaciones Antropológicas, Instituto de Investigaciones Históricas, Instituto de Investigaciones Estéticas, 2000) 275-303. Para el caso de Tucumán, véase Christophe Giudicelli, "Encasillar la frontera. Clasificaciones coloniales y disciplinamiento del espacio en el área Diaguito-Calchaquí, siglos XVI- XVII”, Anuario del IEHS 22 (2007): 161-211.

10. "Visita de 1560 (Anónimo)", No hay caciques ni señores, ed. Hermes Tovar Pinzón (Barcelona: Sendai Ediciones, 1988) 39. 
Fieros animales [que] tienen por costumbre de sustentarse de carne humana, y saliendo de sus propias casas y poblazones se meten por las de sus vecinos y comarcanos, los cuales tienen casi despobladas con inhumana crueldad, porque como gente ya hecha y acostumbrada a estos males, con rústica desvergüenza han cobrado fama de valientes y temidos de todas las otras gentes, y pocos de estos bárbaros se meten con gran audacia entre pueblos de muchos naturales y los arruinan y destruyen con esta insaciable gula que de comer carne humana tienen. ${ }^{11}$

No obstante, a medida que los vecinos de las ciudades de Ibagué, Cartago, Timaná, La Plata y Buga conocían mejor a los pijaos, fueron diseñando una nueva geografia étnica de la cordillera Central. Según el padre Simón, la gran nación pijao estaba dividida en pequeñas provincias: Cutiba, Ayape, valle de las Hermosas, Irico, Paloma, Ambeima, Amoya, Tumbos, Coyaimas, Mayto, Mola, Atayma, Cacataima y Tuamo, todas muy cercanas a Ibagué. Agrega Simón que, a pesar de la pluralidad étnica, todos los nativos tenían la misma lengua, costumbres, religión y "disposición de cuerpos y cabezas". ${ }^{12}$

Los pijaos fueron adquiriendo un protagonismo cada vez más importante. A partir de la década de 1560 se les acusó de cometer robos, destrozos y hasta asaltos a las ciudades fronterizas ubicadas a ambos lados de la cordillera Central. Por ejemplo, en 1567, el gobernador de Popayán, don Álvaro de Mendoza y Carvajal, informó al Consejo de Indias que había ayudado a levantar el cerco que los pijaos y los paeces mantenían en la ciudad de San Vicente de Páez. Los indios atacaban diariamente a los pocos vecinos españoles, y la geografia de la zona era tan "áspera" que hacía imposible que se lanzara una ofensiva mayor, pues recorrer la tierra con caballería era imprudente, debido a que los indios emboscaban a los españoles en los pasos más estrechos.

Mendoza y Carvajal se conformó con socorrer a los colonos, pero anotó que era necesario completar la conquista de todos los indios, debido a que este territorio era limítrofe con la villa de La Plata y con el camino que comunicaba al sur de la provincia de Popayán con el Nuevo Reino de Granada. También ordenó repoblar la villa de Neiva, que era asaltada constantemente por los mismos pijaos. Esta última fue ubicada en un sitio más al norte, seguro y de mejor temple, cercano a unas minas de plata, y desde donde españoles y nativos podían defenderse de los pijaos, "grandes comedores de carne umana". ${ }^{13}$

11. Fray Pedro de Aguado, Recopilación Historial, t. 2, ed. Juan Friede (Bogotá: Biblioteca de la Presidencia de la República, 1956) 489.

12. Simón 262. El cronista Juan de Castellanos escribió en sus Elegías que los pijaos eran: "Gente suelta, feroz, fornida, basta, /Y en uso de la guerra muy esperta; / Membrudos, bien dispuestos, caras torvas, / Las frentes anchas, las narices corvas. / Selváticos, caribes, atrevidos / Todos en general, y en cuanto grado, / Que muertos pueden ser, mas no rendidos / A condiciones de servil estado". Véase Juan de Castellanos, Elegías de varones ilustres de Indias, ed. Gerardo Rivas Moreno (Bogotá: Fundación para la Investigación y la Cultura, 1997) 916.

13. AGI, Sevilla, Quito, 16, r. 5, n. 11, ff. 1r-v. 
Por último, el gobernador Mendoza y Carvajal autorizó al capitán Hernán Pérez para que poblara la ciudad de los Ángeles del Nuevo Potosí, en la cuenca del río Prado. Con esta fundación, se aspiraba a que cesaran los ataques de los pijaos, se normalizara el tránsito entre el Nuevo Reino y Popayán, se afianzara el poblamiento hispánico en el valle del Magdalena y se explotaran las minas de plata de la zona. ${ }^{14}$

Para contrarrestar estas invasiones, se organizaron expediciones militares en contra de los temibles pijaos. Sin embargo, los asaltos continuaron. En 1569 los pijaos destruyeron la villa de Neiva y la recién fundada ciudad de los Ángeles del Nuevo Potosí, asesinaron a todos sus vecinos, cortaron la comunicación entre Popayán y el Nuevo Reino de Granada y asaltaron los hatos y estancias de Tocaima e Ibagué. ${ }^{15}$ Tres años después, asaltaron la villa de La Plata. En este último centro urbano, 15 españoles perecieron y las mujeres se refugiaron en la selva, lo que obligó a los pocos sobrevivientes a asentarse en las estancias y hatos. ${ }^{16}$ En 1570, el gobernador Mendoza y Carvajal escribió desconsolado a Felipe II que los pijaos habían devorado en menos de dos décadas más de 20,000 indios que habitaban en las jurisdicciones de las villas de Neiva y Los Ángeles, por lo que consideraba que la conquista de esos "caribes" era "cosa ymportantísima" ${ }^{17}$

Los ataques no se limitaron al valle del río Magdalena, sino que los pijaos osaron amenazar los repartimientos cercanos a Popayán. Antonio de Alegría, procurador de la ciudad, declaró en 1570 que los pijaos y paeces se habían aliado para atacar el pueblo de Guambia - un repartimiento del mestizo Francisco de Belalcázar-, donde incendiaron la iglesia, robaron los ornamentos y devoraron al sacerdote, y que en 1572 quemaron la neófita urbe de San Vicente de Páez. Sus moradores despavoridos se refugiaron en Timaná y Popayán. ${ }^{18}$

En enero de 1576, el gobernador don Jerónimo de Silva le informó al Consejo de Indias que había encontrado la provincia de Popayán en mucha "estrechura y neçesidad", debido a que los paeces y pijaos impedían que se explotaran las minas de Guambia y Caloto, y estaban tan "atrevidos y bellicosos", que atacaban a los viajeros que iban de Cali a Popayán. Para remediar la situación, Silva propuso que se reunieran hombres y pertrechos en estas dos últimas ciudades, pero los asaltos continuaron. $^{19}$

Las noticias sobre los aguerridos pijaos empezaron a preocupar cada vez más a las autoridades de la Audiencia de Santafé. En febrero de 1577, el oidor don Francisco de Anuncibay advirtió a Felipe II que el asunto de los pijaos y paeces era "cosa de mucha ymportançia", por lo que pedía que se capitulara con algún

14. AGN, Bogotá, Residencias Cundinamarca, t. 49, doc. 6, ff. 387r-v.

15. AGN, Bogotá, Miscelánea, t. 1, doc. 359, ff. 920v-923r.

16. AGI, Sevilla, Quito, 16, r. 8, n. 24, f. 98 v.

17. AGI, Sevilla, Quito, 16, r. 5, n. 12, f. 2v.

18. AGI, Sevilla, Patronato, 233 , r. 81, f. $35 \mathrm{v}$.

19. AGI, Sevilla, Quito, 16, r. 8, n. 21, f. 1r. 
vecino rico para que conquistaran. Anuncibay retomó todos los argumentos que circulaban entre los vecinos del Nuevo Reino y Popayán: los nativos eran por excelencia antropófagos y su "inhumanidad" los llevaba a cometer crímenes horripilantes; tenían carnicería pública donde se vendían cuartos de indios y "lo que nunca se a leído, que si captivan un yndio se lo cargan a cuestas y corriendo con el vivo le van comiendo las orejas y narices y manos". ${ }^{20}$

Figura 1. Teatro de la guerra pijao, 1562-1611

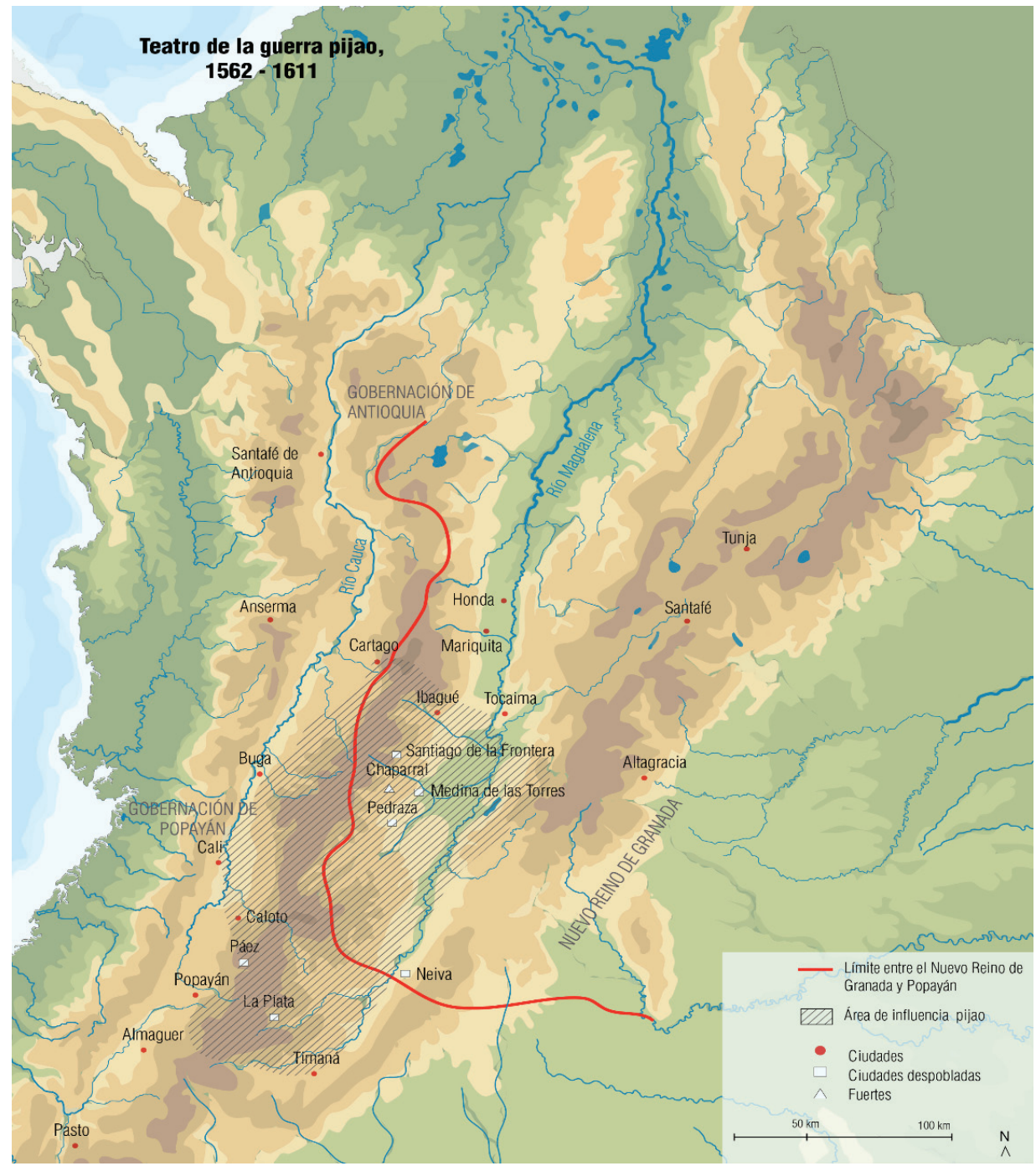

Fuente: Elaboración propia.

20. AGI, Sevilla, Santa Fe, 16, r. 21, n. 73, f. 1v. 
Pocos meses después, el mismo oidor Anuncibay informó a los miembros del Consejo de Indias la gravedad de la situación. Pijaos y paeces sostenían una alianza que ponía en riesgo la comunicación del Nuevo Reino de Granada con el Perú; además, habían despoblado a Neiva y San Vicente de Páez y mantenían en "perpetuo sobresalto" a Ibagué, Timaná y San Juan de Trujillo de Iscancé. Anuncibay solicitó al rey que se ordenara la esclavitud perpetua de estos indios, pues, por ser "gente belicossa y pobre y que por ser gente vagamunda como harabes, que no tienen asiento cierto", la conquista se hacía mucho más larga y dificultosa, "aunque se tiene notiçia que poseen la tierra más rrica que ay en el mundo de oro". ${ }^{21}$ La solicitud del oidor Anuncibay encerraba varios tópicos que eran fundamentales para legitimar una empresa de conquista: antropofagia, belicosidad, behetría y riqueza aurífera. Los ingredientes necesarios para lanzar una ofensiva a gran escala. ${ }^{22}$

Al unísono con las peticiones de los oficiales de la Audiencia de Santafé, el gobernador de Popayán, don Bartolomé de Mazmela, escribió a Felipe II en 1576 para informar que los pijaos y paeces habían aumentado sus asaltos en Buga, Cartago, Popayán y La Plata, por lo que solicitaba al rey que se pudieran esclavizar a los indios durante 15 años. ${ }^{23}$ Esta petición estaba directamente ligada a la necesidad de obtener mano de obra para la explotación de oro en las minas, debido a que el impacto de las enfermedades, la violencia cotidiana y el trabajo forzado causaron en toda la gobernación de Popayán un fuerte descenso de la población nativa. ${ }^{24}$

Con el fortalecimiento de la presencia española a partir de la década de 1570 , en la cordillera Central y en la zona ubicada entre los nacimientos de los ríos Cauca y Magdalena se circunscribió con más precisión la zona pijao. Al final de la campaña que lanzó el experimentado Diego de Bocanegra en 1572, se limitó el área pijao desde el nevado del Huila al sur, hasta las cercanías de la ciudad de Ibagué al norte, y desde la vertiente izquierda de la cordillera Oriental hasta el otro lado de la cordillera Central, muy cerca de las ciudades de Buga y Cartago. ${ }^{25}$

En este extenso territorio, los indios resistían con tenacidad e impedían que los españoles se instalaran en sus tierras, hasta la campaña de guerra a "fuego y sangre" que llevó a que Bocanegra fundara en 1572, a orillas del río Ortega, la ciudad de Santiago de la Frontera, un pequeño fuerte que servía para que los conquistadores y sus auxiliares indígenas realizaran razias en contra de los nativos. Sin embargo,

21. AGI, Sevilla, Santa Fe, 16, r. 21, n. 76, f. 2r.

22. La argumentación de calificativos negativos para legitimar la conquista no fue particular del Nuevo Reino de Granada, ya que también en otras regiones de América se utilizaron estos adjetivos. Véase Guillaume Boccara, Los vencedores. Historia del pueblo mapuche en la época colonial (Santiago: Línea Editorial IIAM / Universidad Católica del Norte, 2007) 225-253.

23. Juan Friede, Fuentes documentales para la historia del Nuevo Reino de Granada. Desde la instalación de la Real Audiencia en Santafé, t. 7 (Bogotá: Biblioteca Banco Popular, 1975) 97.

24. Juan Villamarín y Judith Villamarín, "Native Colombia: Contact, Conquest and Colonial Populations", Revista de Indias 63.227 (2003): 118-120, doi: 10.3989/revindias.2003.i227.554.

25. Julio César Cubillos, "Apuntes para el estudio de la cultura pijao", Boletín de Arqueología 2.1 (1946): 51-52. 
otros centros urbanos eran sitiados constantemente por pijaos y paeces; por ejemplo, sobre la villa de La Plata se informó en 1582 que estos últimos estaban "exercitadisimos en la guerra y son muy valientes", pues mantenían sitiada a esta población, obligando a sus vecinos a "cercar el pueblo de dos tapias en alto que no ay otro en todo el Pirú cercado". ${ }^{26}$ Todos los intentos por establecer un centro urbano entre ellos terminaban como un fracaso sangriento. Las tentativas del capitán Bocanegra para establecer centros urbanos terminaron siempre en desastre.Y, aunque Bocanegra fundó la ciudad de Santiago de la Frontera, los ataques de los indios obligaron a sus vecinos a trasladarla en 1574 . Sus habitantes se asentaron a orillas del río Coello y dos años después la abandonaron definitivamente. ${ }^{27}$

Nuevamente, en 1586, Bocanegra entró en territorio pijao y fundó en la mesa de Chaparral la ciudad de Medina de las Torres, pero "los yndios de junta y mano armada binieron sobre ella de noche y la quemaron y abrasaron y echaron de la tierra a los vezinos". ${ }^{28}$ Bocanegra obligó a los habitantes a reconstruir la ciudad a orillas del río Tetuán, pero una epidemia de viruela barrió a los naturales que servían en el cultivo de maíz, lo que forzó a los españoles a refugiarse en Ibagué hasta que, por última vez, en 1588, se repobló la ciudad en el río Coello, como parte de una estrategia más amplia que buscaba convertirla en un punto de avanzada hacia el territorio pijao. Medina de las Torres fue desmantelada definitivamente en $1592 .^{29}$

Pero todavía algo peor estaba por suceder. En 1590 la Audiencia de Santafé nombró a Bernardino Mojica de Guevara como gobernador de la parte alta del valle del río Magdalena, e incluyó en su jurisdicción a Ibagué y Timaná. ${ }^{30} \mathrm{La}$ guerra se extendió como pólvora. La ciudad de San Miguel de Pedraza, fundada en 1592 por el mismo Bocanegra, fue asolada y destruida rápidamente por los pijaos. Como consecuencia de esta situación, el valle del Magdalena y la cordillera Central se convirtieron en refugios para todos los grupos e individuos deseosos de escapar del control colonial. Dicho de otro modo, esta zona se afianzó como una verdadera frontera interna.

En síntesis, el nombre "pijao" fue una designación genérica. Primero, es claro su origen colonial, pues se trata de una extensión metonímica del nombre "pinaos" a una población y a un territorio que alcanzó su circunscripción definitiva al finalizar el siglo XVI. Segundo, el vocablo "pijao" no procede de ninguna autodenominación (ninguno de los grupos designados así lo reconocía como propio). Tercero, tampoco era una designación genérica otorgada por sus vecinos o rivales,

26. "Memorial que da Fray Gerónimo Descobar predicador de la orden de Sant Agustín al Real Consejo de Yndias en lo que toca a la provincia de Popayán (1582)", Relaciones y visitas 406.

27. Manuel Lucena Salmoral, Historia extensa de Colombia, vol. 3, t. 2, dir. Academia Colombiana de Historia (Bogotá: Ediciones Lerner, 1965) 129.

28. AGN, Bogotá, Poblaciones, t. 46, f. 720r.

29. Adolfo Triana Antorveza, La colonización española del Tolima. Siglos XVI y XVII (Bogotá: Funcol / Cuadernos del Jaguar, 1992) 238.

30. AGI, Sevilla, Santa Fe, 94, n. 5, f. 87r. 
como ocurría en tantos casos. Lo interesante aquí es que "pijao" fue el vocablo que se utilizó para designar al enemigo y su territorio fue sinónimo de región rebelde. Además, no era un nombre exclusivo, debido a que en ningún momento los colonos de Ibagué o de las otras ciudades fronterizas perdieron de vista que estos pijaos eran parte de una nación más grande: guaruos, tamagalaes, coyaimas y natagaimas. Todos hablaban la misma lengua y, en ocasiones, eran aliados y parientes, o en otras, enemigos acérrimos.

\section{El fraccionamiento pijao}

La aparición de un foco pijao en la suela plana del río Magdalena, en un lugar que apenas era un valle y que no parecía compartir nada con los pijaos "originales" - es decir, los de la cordillera Central—, plantea una serie de problemas. En rigor, no se puede descartar la existencia de grupos aislados hablantes de la lengua pijao, que al parecer estaba muy extendida en el momento de la conquista. ${ }^{31}$ Según el presidente Juan de Borja, sin duda uno de los españoles que más prestó atención al idioma de los naturales: "Todos los yndios del nombre común de pixaos en llano y sierra hablan una misma lengua con poca diferencia de algunos vocablos y son conformes en sus bárbaras costumbres, ritos y ceremonias y en la manera de las armas y exersiçio de la guerra". ${ }^{32}$

La zona que ocuparon los coyaimas estaba ubicada entre los ríos Saldaña y Magdalena. Este grupo se destacó desde finales del siglo XVI por las alianzas que establecieron con los españoles. Así como en otros lugares de la monarquía católica, los colonos ibéricos explotaron en el Nuevo Reino de Granada las divisiones y rivalidades existentes entre los diferentes grupos indígenas para sellar pactos de amistad y establecer alianzas que les permitieran dominar a otros nativos. Su papel en la guerra convirtió a los coyaimas en verdaderos conquistadores y los privilegios que reclamaron a lo largo del periodo colonial reflejaban sus expectativas de poder actuar como verdaderos conquistadores. ${ }^{33}$ Por ejemplo, en 1603, Alonso Vicario, un vecino de Ibagué, declaró que la mejor forma para conquistar a los pijaos era:

Atraer a nuestra amistad a los indios de lo llano y aplazarlos de manera que acudan de buena gana cuando los españoles los llamaren, porque siendo como son, indios tan belicosos y enemigos capitales de los otros de la sierra, se hace la guerra de nuestra parte con mucho mejor aparejo

31. La lengua pijao se hablaba no solo en la cordillera Central, sino también en el valle del río Magdalena. Al parecer estaba emparentada con el idioma panche y hacía parte de la familia lingüística caribe.Véase Manuel Lucena Salmoral, "Datos antropológicos sobre los Pijao", Revista Colombiana de Antropología 12 (1963):367-368, doi: 10.22380/2539472X.1696; Santiago Paredes Cisneros, "Lengua pijao como lengua franca en las gobernaciones de Popayán y Neiva, siglos XVI-XVII”, Fronteras de la Historia 23.1 (2018): 40-66, doi: 10.22380/20274688.311.

32. AGI, Sevilla, Patronato, 196, r. 27, ff. 989r-v.

33. Matthew Restall y Felipe Fernández-Armesto, Los conquistadores: una breve introducción (Madrid: Alianza Editorial, 2013) 106. 
llevando a los dichos coyaimas por amigos, porque en cuanto es el saber de la tierra y atalayarla son habilísimos y huelgan en servir a los españoles en esto con fidelidad por tener aparejo de vengarse. ${ }^{34}$

Los españoles en las fronteras de las Audiencias de Santafé y Quito estaban muy conscientes del carácter arbitrario de sus enunciados. Sabían que sus clasificaciones eran tan solo una manera de ajustar la realidad del mundo indígena a sus propias necesidades. ${ }^{35}$ De hecho, era tan fuerte la arbitrariedad de la categoría "nación" aplicada a los indios de las tierras del Magdalena y de la cordillera Central, que los grupos que encasillaron estuvieron sujetos a lo largo del periodo colonial a una serie de reajustes y de modificaciones a veces muy profundas. Así, los coyaimas pasaron de ser enemigos de los conquistadores ibéricos a aliados en el momento de emprender la guerra contra los pijaos. El presidente Borja, por ejemplo, afirmó que con los coyaimas había "variedad y confusión", pues su imagen de "indios de guerra" se transformó en "indios amigos" al ser reubicados a orillas del río Saldaña y al acompañar a los españoles como guías, intérpretes y guerreros. ${ }^{36}$ También otro experto militar, Domingo de Erazo, sostuvo en un informe fechado en 1607, que los coyaimas eran "neutrales, que biben entre la paz y la guerra conforme a la ocasión de su provecho o daño". 37

Como suele ocurrir, la mejor información sobre las prácticas clasificatorias de los españoles en estas zonas de frontera se encuentra en documentos relativos a la inclusión ordenada de las naciones que se consideraban como "rebeldes". Este es el caso del informe presentado al Consejo de Indias en 1596 por el exgobernador del Chocó Melchor de Salazar. Según él, en la provincia de Popayán habitaban aproximadamente 5,000 indios que, según la ubicación de sus clasificadores, eran denominados con nombres distintos. Así, los nativos que en Ibagué eran llamados como natagaimas, en Cartago y Buga eran denominados putimaes, y en Popayán, Caloto y Neiva se les nombraba pijaos. Para Salazar, estos tres apelativos servían para designar a un mismo grupo étnico, pero clasificarlo de forma distinta. Se trataba de

34. Enrique Ortega Ricaurte, Los inconquistables. La guerra de los Pijaos, 1602-1603 (Bogotá: Ministerio de Educación Nacional, 1949) 295.

35. Christophe Giudicelli, “'Identidades' rebeldes. Soberanía colonial y poder de clasificación: sobre la categoría calchaquí (Tucumán, Santa Fe, siglos XVI-XVII)", América colonial. Denominaciones, clasificaciones e identidades, eds. Alejandra Araya Espinoza y Jaime Valenzuela Márquez (Santiago: RiL Editores, 2010) 137-172.

36. AGI, Sevilla, Patronato, 196, r. 27, f. $994 \mathrm{v}$.

37. Mauricio Arango Puerta, transcr., "Informe de Domingo de Erazo sobre la guerra de los indios pijaos, 1606”, Historia y Sociedad 33 (2017): 388, doi: 10.15446/hys.n33.63306. Sobre la circulación y apropiación de los conocimientos bélicos, en el caso de Domingo de Erazo, véase Jaime Valenzuela Márquez, "Del Biobío al Magdalena: para una historia conectada de experiencia militares y fronteras imperiales. Domingo de Erazo (1592-1617)", Trascendiendo fronteras. Circulaciones y espacialidades en torno al mundo americano, eds. Fernando Purcell y Ricardo Arias Trujillo (Bogotá: Universidad de los Andes / Pontificia Universidad Católica de Chile, 2020) 1-34. 
los pijaos, a quienes se les atribuía el haber devorado 10,000 indios cristianos de Popayán, Caloto, Buga, Caloto, Cali, Cartago, Ibagué, Neiva, Timaná y La Plata:

\begin{abstract}
Puestos todos estos pueblos como en la çircunferençia de una $\mathrm{O}$, el punto de su medio o çentro es la tierra donde avitan estos yndios de guerra pijaos y putimaes, los quales acavaron a Neyba, despoblaron La Plata, quemaron a Paes, desterraron a Buga, consumen a Carthago, acaban a Ybague, rroban las mercaderías, matan los españoles, comenselos sin perdonar frayles ni clérigos ni los propios yndios que cauptiban, sirviendo de sepulcros de umana carne sus ynsaçiables y malignos cuerpos. ${ }^{38}$
\end{abstract}

La consecuencia inmediata fue que no se buscó hasta dónde se podía extender la apelación "pijao", sino que se encerró en esta clasificación a todos los indios de la cordillera Central. Los años de 1590 a 1611 fueron, por lo tanto, un periodo de claro endurecimiento taxonómico, un fenómeno particularmente notable en el territorio del valle del río Magdalena y de la cordillera Central, donde aquellos indios de los que nadie, ni siquiera las tropas encargadas del "castigo", podía determinar si eran pijaos, coyaimas, natagaimas o putimaes, debido a que estas "identidades" estaban superpuestas. Dicho de otro modo, el trabajo conceptual efectuado durante la guerra y en los años siguientes terminó por forjar una nación enemiga, algo que, como se verá, tendió a generalizarse en las dos primeras décadas del siglo XVII.

\title{
3. "Esperando cada día al enemigo"
}

A partir de la década de 1580, los ataques de los pijaos empezaron a tener un protagonismo más importante, muy nefasto para la sociedad colonial en general, debido a que se les culpaba de todos los males padecidos por los colonos españoles. Muy pronto, los cabildos de las ciudades fronterizas a ambos lados de la cordillera Central empezaron a denunciar las "invasiones" y las expediciones punitivas que realizaban los “indios de guerra”. Por ejemplo, en 1577, el gobernador de Popayán, Sancho García del Espinar, le informó al rey que toda su provincia se encontraba en "mucha estrechura y necesidad" por estar rebelados los paeces y pijaos, quienes atacaban las minas de Caloto y el repartimiento de Guambia, y hasta asaltaban las caravanas de los viajeros que transitaban entre Cali y Popayán. ${ }^{39}$

Los asaltos de paeces y pijaos provocaron que en 1582 los vecinos de Caloto trasladaran la ciudad hacia un punto intermedio del camino que comunicaba a Cali con Popayán. El gobernador García del Espinar informó al rey que los ataques de los indios habían provocado el despoblamiento de Neiva, San Vicente y La Plata. Le hizo saber que los habitantes buscaron refugio en otros centros urbanos, mientras que las casas y las iglesias fueron incendiadas, "profanando los cálices y

38. AGI, Sevilla, Quito, 24, n. 38, f. 4v.

39. AGI, Sevilla, Quito, 16, r. 8, n. 21, f. 70r. 
las demás cosas del culto divino, bebiendo con ellos en borracheras y vistiéndose los hornamentos en ellos para baylar". Dijo que, así como los españoles vendían "vacas y carneros", los pijaos tenían carnicerías donde vendían la carne de los indios enemigos. ${ }^{40}$

Al año siguiente, el nuevo gobernador de Popayán, Juan de Tuesta Salazar, afirmó que era necesario "pacificar" a los pijaos, paeces y toribíos que mantenían en estado de sitio a las ciudades de Popayán, Cali y Buga, pues los indios eran "belicosos y guerreadores y naçidos y criados en ello, aunque agora están seguros, en la primera borrachera que hagan salen unos nuevos ánimos y a traycion por los caminos y provinçias de indios que están paçificados y los matan y comen" ${ }^{41} \mathrm{El}$ ataque de los pijaos no ocurrió en el sur, como pensaban las autoridades coloniales, sino en la jurisdicción de Cartago, una zona mucho más desprotegida y que les permitía mayor movilidad, pues podían fácilmente atravesar la cordillera Central en busca de refugio. En 1584, el gobernador Tuesta Salazar envió a Pedro Sánchez del Castillo en compañía de 23 soldados a "castigar" a los pijaos que habían atacado el pueblo del Quindío. El resultado de la entrada fue contundente: 80 guerreros pijaos degollados, un cacique empalado, 23 indias y niños ejecutados, tres soldados españoles muertos y el mismo número capturado por los pijaos. ${ }^{42}$

Ese mismo año, los vecinos de Caloto se quejaban de la zozobra en la que vivían debido a los ataques de pijaos y paeces. Pedro de Castro, un visitador enviado por la Audiencia de Quito sostuvo que eran tan pocos y tan jóvenes los soldados para la defensa de la ciudad, que en cualquier momento los nativos podrían "rebelarse". Caloto contaba con dieciocho encomenderos mal apertrechados, por lo que pedía que los vecinos de la destruida San Vicente de Páez se asentaran en esta ciudad y que los cabildos de Popayán, Cali y Almaguer enviaran tropas para la defensa. ${ }^{43}$

Los ataques de los pijaos no cesaron con el paso de los años. Periódicamente, los indios asaltaban estancias, hatos y reales de minas de las ciudades de la gobernación de Popayán. Por ejemplo, en 1596, Melchor de Salazar informó al Consejo de Indias que los pijaos habían asesinado a 40 indios en una estancia de Cartago y que, en el camino que comunicaba a este último centro urbano con Ibagué, asaltaban casi diariamente a los viandantes. Además, supuso que un ataque a la propia ciudad de Cartago no debía demorar, pues sus casas estaban construidas con techo de paja y "cada día se presume la an de quemar y robar y acabar y consumir". ${ }^{44}$ El temor continuó en los años siguientes.

En 1599, el gobernador de Popayán, Francisco de Berrío, escribió al rey que los asaltos de estos indios se realizaban mensualmente, en caminos de los valles de

40. AGI, Sevilla, Quito, 16, r. 8, n. 24, f. 84r.

41. AGI, Sevilla, Quito, 23, n. 8, f. 6r.

42. Friede, Fuentes documentales 225-228.

43. ACC, Popayán, Libro Capitular, años 1584-1589, ff. 38v-39v.

44. AGI, Sevilla, Quito, 24, n. 38, f. 5r. 
los ríos Cauca y Magdalena, un territorio que era considerado como la "mexor y la más fértil tierra de toda esta provinçia donde por ser montaña tienen disposición para fortificarse". Agregaba Berrío que la guerra a los pijaos debía realizarse abriendo dos grandes frentes: uno desde Popayán y otro desde el Nuevo Reino, lo que permitiría la ampliación de la frontera minera y la pacificación definitiva de "los más ynsolentes y bárbaros enemigos que se han conoçido en el mundo". ${ }^{45}$ En 1601, el nuevo gobernador de Popayán, don Vasco de Mendoza y Silva, informó al rey Felipe III que la comunidad de Cartago estaba tan "medrossa" que habían cercado la ciudad con tapias. ${ }^{46}$

En 1603, los pijaos lanzaron una ofensiva en diferentes frentes. Primero, asaltaron un presidio de la Mesa de Ibagué, distante a seis leguas de la ciudad, con tanta "furia", que asesinaron a 15 indios y un español. Segundo, en Cartago ejecutaron a varios nativos en una encomienda cercana a la ciudad. Por último, en Tocaima hicieron lo propio con siete naturales más. Por temor a nuevas irrupciones, los vecinos de Ibagué andaban siempre con las “armas a cuestas". Era tal la situación de zozobra que la Audiencia de Santafé ordenó al gobernador Mendoza y Silva que alistara tres compañías de infantería para que realizaran expediciones desde Buga, Cartago y Timaná, y el corregidor de Mariquita, Juan de Aguilar, debía apertrechar dos expediciones que partirían desde Ibagué y Tocaima. ${ }^{47}$ Por ejemplo, el cabildo de Cartago escribió que, desde un cerro cercano a la ciudad, los pijaos daban "voces amenazándola que la han de quemar, que por ser el pueblo pajizo y estar metido en una montaña todos estamos con el temor y recelo". ${ }^{48}$ En Ibagué, los encomenderos y religiosos andaban armados "esperando cada día al enemigo". ${ }^{49}$ En Timaná, un jesuita que la visitó por la misma época notó que los pijaos se acercaban a la ciudad "y blandeando sus lanças desafian y hacen burla de los españoles". 50

El 18 de julio de 1606, los pijaos atacaron Ibagué. Primero asaltaron el arrabal de la ciudad, donde asesinaron a los indios de servicio e iniciaron, según el padre Simón, un festín caníbal como "lobos rabiosos". Posteriormente, arremetieron hasta la plaza de la población y asesinaron a todos los que encontraban a su paso:

Parecía un día de juicio, el alboroto de la plaza y toda la ciudad: aquí sonaban voces, allí gritos de niños y mujeres y muchachos que los daban a sus maridos y padres, acullá gemidos mezclados con voces de caracoles y trompetillas de los bárbaros que discurrían por todas partes con furia de demonios, pegando fuego a cuanto había. Los torbellinos de llamas remolineando con el huracán que entonces se levantó lamían furiosamente las alturas y aun cumbres de las casas convecinas.Y cuando no alcanzaban a esto las centellas que saltaban, por ser las casas pajizas, las hacia todas de

45. AGI, Sevilla, Quito, 16, r. 10, n. 26, ff. 1v-2r.

46. AGI, Sevilla, Quito, 16, r. 11, n. 27, f. 193v.

47. Ortega Ricaurte 22-26.

48. Ortega Ricaurte 44.

49. Ortega Ricaurte 71.

50. ARSI, Roma, Novi Regni et Quito, t. 12, f. 42v. 
igual ceniza. El humo los hacía ciegos y llorosos a todos los demás la ocasión, los gritos de los bárbaros eran intolerables, la confusión y temores no les daban una hora de vida. ${ }^{51}$

En total, los pijaos quemaron 70 casas, asesinaron a 60 personas y capturaron a varias mujeres y niños españoles. Las invasiones de estos indios a las diferentes ciudades del Nuevo Reino y Popayán procedían siempre del mismo lugar: la cordillera Central. Sin embargo, los mismos colonos identificaron a la provincia de Amoyá como el verdadero corazón de la nación de los pijaos. Ubicada al sur de la ciudad de Ibagué, sus habitantes contaban con tierras fértiles para la agricultura y caminos que les permitían comunicarse con la suela plana del valle del río Magdalena e, incluso, atravesar la cordillera Central para acceder a la gobernación de Popayán.

El baqueano Diego de Bocanegra escribió en 1603 que Amoyá, Ambeyma, el valle de Maynto, Tetuán, Otayma y Cacatayma eran "toda la fuerza mayor" de los pijaos; calculó su población en unos mil habitantes y sostuvo que en el resto del territorio había "ladroneras de mucho bastimento y comida do [sic] se sustentan en la guerra". ${ }^{52}$ Cuatro años después, el presidente Borja informó en su Relación $y$ discurso sobre la guerra que el principal objetivo que había que atacar era la provincia de Amoyá, pues tenía fama de "inexpugnable" y que desde que allí se había derrotado a la hueste del capitán Francisco de Trejo a mediados del siglo XVI. ${ }^{53}$ Borja también observó que, debido a las expediciones lanzadas por lo españoles, los pijaos mantenían una constante migración interna. Los habitantes de las provincias de Maynto, Ambeyma, Paloma, Otaima y Cacatayma se habían refugiado en Amoyá..$^{54}$

Así que el territorio pijao se presentaba como una zona donde la conquista se hacía lenta debido a la resistencia de sus habitantes y a las grandes diferencias topográficas de la zona. No obstante, la región era de mucho interés económico para los colonos e incluso para centros urbanos tan alejados como Cartagena, Santafé, Tunja y Quito. Además de privar a los españoles de una reserva importante de mano de obra, la insumisión de los indios les prohibía el control de unas tierras reputadas por su riqueza minera, su fertilidad y su importancia estratégica. La inseguridad que prevalecía en los caminos cerraba asimismo a los vecinos de ciudades como Ibagué, Tocaima y Timaná de otra riqueza importante: el ganado cimarrón que pastaba en el valle del río Magdalena.

Esta excesiva riqueza se convirtió en el argumento perfecto para lanzar campañas militares hacia la zona. Por ejemplo, en octubre de 1597, el presidente de la Audiencia de Santafé, don Francisco de Sande, escribió al rey para informarle que la dominación de los pijaos era "cosa ymportantissima, más que lo de los chichimecas en la Nueva Spaña”.Y este oficial lo sabía muy bien, pues se había desempeñado como

51. Simón 380-381.

52. Ortega Ricaurte 44.

53. AGI, Sevilla, Patronato, 196, r. 27, f. $994 \mathrm{v}$.

54. AGI, Sevilla, Patronato, 196, r. 27, f. 1002v. 
oidor del tribunal de México, donde se destacó en la guerra contra los chichimecas. A reglón seguido, Sande argumentó que la zona comprendida entre los ríos Cauca y Magdalena debía conquistarse por las armas, debido a que era un "thesoro de oro, criaderos y minas del". También sostuvo que este archipiélago no solo se suscribía a la zona pijao, sino que se extendía por más de 100 leguas hasta la villa de Mompox. ${ }^{55}$

El territorio pijao presentaba un interés económico por las reservas de mano de obra indígena que entrañaba para todo tipo de cazadores de esclavos o encomenderos deseosos de aumentar sus feudos mediante la organización de verdaderas razias disfrazadas como campañas de pacificación. Desde este punto de vista, parece evidente que la reclasificación como "pijaos" - indios de guerra por antonomasia - de los naturales ubicados en la parte sur de la cordillera Central seguía una lógica económica. Para incentivar la ampliación de la frontera minera, Felipe II ordenó en 1580 que los pijaos capturados en guerra fueran esclavizados con el fin de frenar los asaltos a ciudades y caminos, atraerlos a la fe católica y, sobre todo, erradicar la práctica del canibalismo entre ellos. ${ }^{56}$

El discurso sobre los pijaos se endureció con el paso de los años. En la época, era fácil hacer una ecuación con bestialidad, irracionalidad y barbarie, y aquellos que la hacían podían acudir a la doctrina aristotélica para justificar la dominación española sobre los indios como natural y necesaria. En 1604, el capitán Juan Bautista de Ávalos afirmó que los asaltos a las caravanas de españoles que transitaban entre Tocaima y Timaná eran realizados por los coyaimas y los tamagalaes, "traidores, salteadores, robadores y matadores", e "indios sin Dios ni rey ni ley, enemigos mortales de la generación humana". ${ }^{57}$ El presidente Borja los describió a principios del siglo XVII como gente "feroz". Sostenía que:

No tienen ninguna inteligencia de interés ni granjería, ni otra ocupaçion ni ofiçio más de la inquietud y exerçiçio de la guerra y son muy valientes y determinados en ella y grandes y sufridores de travajos y de notable valor y ánimo en rreçivir la muerte y qualquier género de tormento sin quexarse ni hazer desvío ni señal de sentimiento más que si fuesen insensibles. ${ }^{58}$

También el jesuita Gonzalo de Lyra, quien recorrió la zona de Timaná en 1609, escribió que los pijaos "más parecen fieras que hombres, tan crueles que ninguno perdonan, tan bestiales que quando cogen golpe de gente, aunque sean otros indios ponen carnizeria pública de carne humana, de gusto tan estragado en esta parte que desentierran los cuerpos para comerlos". Según el misionero jesuita, los pijaos parecían "buytres o cuervos", pues había sido testigo cuando anduvo por el valle de Neiva de que los indios desenterraron un cadáver, que había sido sepultado seis

55. AGI, Sevilla, Santa Fe, 17, r. 14, n. 140, f. 1v.

56. Richard Konetzke, Colección de Documentos para la historia de la formación social de Hispanoamérica, 1493-1810, t. 1 (Madrid: Consejo Superior de Investigaciones Científicas, 1953) 531-532.

57. Enrique Otero D'Costa, "Campaña contra los indios pijaos en 1603 y 1604”, Archivo Historial 2.22 (1920): 425.

58. AGI, Sevilla, Patronato, 196, r. 27, f. 991v. 
días atrás, para consumirlo. Era tal el apetito caníbal de los pijaos que cuando capturaban a un enemigo "los rajan y dan cuchilladas para beberles la sangre"; además, a los cautivos se les paseaba por las diferentes aldeas indígenas y en las "fiestas y borracheras" les amputaban un "braço y en otra otro y así van por todas mientras dura, cortando a cada uno de donde más gusto les da". ${ }^{59}$ La guerra aparecía entonces como un modo privilegiado para adquirir nuevos individuos e incorporarlos al seno de sus sociedades por vía del sacrificio antropofágico o por el camino de la naturalización y las alianzas matrimoniales.

Existen motivos para considerar que la creciente conflictividad hispano-pijao desde finales del siglo XVI procedía directamente de las prácticas guerreristas de los colonos de Ibagué, Cartago, Timaná, Caloto, Buga y Tocaima. En 1593, Felipe II permitió esclavizar a los pijaos por diez años, siempre y cuando fueran capturados en guerra. ${ }^{60}$ El impulsor de la nueva política de esclavización de los pijaos fue el presidente don Antonio González, quien argumentó que había reunido una junta de teólogos en Santafé a imagen de la que se congregó en la Nueva España, cuando se autorizó la esclavitud de los chichimecas. ${ }^{61}$ Para González, la esclavitud de los pijaos se hacía necesaria porque vivían en behetría, practicaban la antropofagia y llevaban más de medio siglo resistiendo a las campañas de pacificación de los españoles. ${ }^{62}$

En el periodo de mayor auge de la guerra hispano-pijao, se escucharon las propuestas más radicales para esclavizar a los nativos. Por ejemplo, en 1611, el contador y veedor Andrés Pérez de Pisa propuso la esclavitud perpetua para los pijaos. Argumentaba que estos indios siempre estaban decididos a "morir antes de subjetarse", pues los que eran enviados a Santafé de Bogotá, a la primera oportunidad huían para regresar a sus provincias. Por tal motivo, Pérez de Pisa proponía que los pijaos se vendieran como esclavos en la lejana Cartagena, o en Zaragoza y Los Remedios. ${ }^{63}$

\section{ARSI, Roma, Novi Regni et Quito, t. 12, f. 143r.}

60. Aunque la práctica de esclavizar a los pijaos ocurría desde mediados del siglo XVI, existen dos antecedentes importantes. El primero fue una cédula de 1580 que permitía esclavizar a los indios capturados en la guerra. El segundo, otra cédula fechada en 1593, la cual autorizó cautivar a todos estos indios por diez años. Ambas directrices tuvieron impacto sobre la población pijao. Por ejemplo, en la década de 1580, había en Santafé de Bogotá pijaos capturados en la guerra que eran utilizados en la construcción de la iglesia de San Francisco. AGN, Bogotá, Historia civil, t. 1 , doc. 8 , f. 231 r.

61. Sobre los debates para legitimar la esclavitud de los chichimecas, véase Alberto Carrillo Cázares, El debate sobre la guerra chichimeca, 1531-1585. Derecho y política en la Nueva España, 2 tomos (México: El Colegio de Michoacán / El Colegio de San Luis, 2000). Sobre el cautiverio de indios y las prácticas de esclavización en otras latitudes americanas, véase Gastón Gabriel Doucet, "Sobre cautivos de guerra y esclavos indios en el Tucumán. Notas en torno a un fichero documental salteño del siglo XVIII", Revista de Historia del Derecho 16 (1988): 59-152.

62. AGI, Sevilla, Santa Fe, 17, r. 8, n. 46, f. 3v.

63. Mauricio Arango Puerta, transcr., "Informe sobre la guerra contra los indios pijaos por el contador y veedor Andrés Pérez de Pisa, 1611”, Boletín Museo del Oro 57 (2017): 75. En el mismo año, el presidente Borja también propuso esclavizar perpetuamente a los pijaos para evitar que 
Todo parece indicar que la cordillera Central funcionaba ante todo como un espacio de insumisión cuyas características terminaban siempre por contaminar, a ojos de las autoridades de Santafé o Popayán, a los grupos indígenas que vivían en ella. Hipotéticamente podría pensarse que el nombre utilizado para designar esa actitud de ruptura de la obediencia era el de "pijao", generalmente extendido al conjunto de los grupos indígenas combatidos por los habitantes de las ciudades y villas asentadas en los valles de los ríos Cauca y Magdalena.

\section{Consideraciones finales}

Los vecinos de algunas ciudades y villas del Nuevo Reino de Granada y Popayán crearon y extendieron la categoría "pijao" para poder acceder a mano de obra barata y, sobre todo, a los ricos yacimientos auríferos de la cordillera Central. A estos conquistadores españoles no les interesaba determinar la realidad exacta de los grupos nativos, sino ajustar esa realidad a sus propias necesidades. Para ello, delimitaron inicialmente una categoría amplia — los pijaos_- y luego la dividieron en parcialidades como Amoyá, Tuamo o Ambeima, entre otras.

Las causas de este reacomodo taxonómico eran varias. Primero, estaba la necesidad de mantener la seguridad de los vecinos españoles; así, una de las primeras acciones para responder a los ataques de los pijaos — además de las acciones militares- fue identificar y establecer los límites y características de esta nación. Posteriormente, los españoles dividieron este grupo en diferentes provincias, lo que les permitió conquistarlos con mayor facilidad. Es decir, la resistencia y las ofensivas de los pijaos obligaron a los europeos a realizar una clasificación del enemigo. Ya no se trataba de simples "bárbaros", como los describieron las primeras huestes a mediados del siglo XVI, sino de identificar y cercar a los responsables de los ataques a estancias, caminos y ciudades.

\section{Fuentes}

\section{Manuscritas}

Archivo General de Indias, Sevilla (AGI)

Santa Fe

Quito

Patronato

Archivum Romanum Societatis Iesu, Roma (ARSI)

Novi Regni et Quito

Archivo General de la Nación, Bogotá (AGN)

Historia civil

reincidieran en "rebeldía con entero conocimiento de nuestras cosas". AGI, Sevilla, Santa Fe, 18, r. 12, n. 122 , ff. $3 \mathrm{v}-4$ r. 
Miscelánea

Poblaciones

Residencias Cundinamarca

Archivo Central del Cauca, Popayán (ACC)

Libro Capitular

\section{Impresas}

Aguado, Fray Pedro de. Recopilación Historial. Tomo 2. Ed. Juan Friede. Bogotá: Biblioteca de la Presidencia de la República, 1956.

Arango Puerta, Mauricio. Transcr. "Informe de Domingo de Erazo sobre la guerra de los indios pijaos, 1606”. Historia y Sociedad 33 (2017): 365-396. Doi: 10.15446/hys.n33.63306.

. "Informe sobre la guerra contra los indios pijaos por el contador y veedor Andrés Pérez de Pisa, 1611”. Boletín Museo del Oro 57 (2017): 58-85.

"Devocionario de Ibagué". San Bonifacio de Ibagué del Valle de las Lanzas. Documentos para su historia. Dir. Enrique Ortega Ricaurte. Bogotá: Editorial Minerva, 1952.

Castellanos, Juan de. Elegías de varones ilustres de Indias. Ed. Gerardo Rivas Moreno. Bogotá: Fundación para la Investigación y la Cultura, 1997.

Friede, Juan. Documentos inéditos para la Historia de Colombia. Tomo 5. Bogotá:Academia Colombiana de Historia, 1957.

- Fuentes documentales para la historia del Nuevo Reino de Granada. Desde la instalación de la Real Audiencia en Santafé. Tomo 7. Bogotá: Biblioteca Banco Popular, 1975.

“Jura Carlos IV en Cali”. Boletín de Historia y Antigüedades 5 (1909):159-167.

Konetzke, Richard. Colección de Documentos para la historia de la formación social de Hispanoamérica, 1493-1810. Tomo 1. Madrid: Consejo Superior de Investigaciones Científicas, 1953.

No hay caciques ni señores. Ed. Hermes Tovar Pinzón. Barcelona: Sendai Ediciones, 1988.

Ortega Ricaurte, Enrique. Los inconquistables. La guerra de los Pijaos, 1602-1603. Bogotá: Ministerio de Educación Nacional, 1949.

Otero D’Costa, Enrique. “Campaña contra los indios pijaos en 1603 y 1604”. Archivo Historial 2.22 (1920): 405-432.

Relaciones y visitas a los Andes. S. XVI. Tomo 1. Ed. Hermes Tovar Pinzón. Bogotá: Colcultura / Instituto de Cultura Hispánica, 1993.

Simón, Fray Pedro. Noticias Historiales de las conquistas de Tierra Firme en las Indias Occidentales. Tomo 5. Ed. Juan Friede. Bogotá: Biblioteca Banco Popular, 1981.

\section{Bibliografía}

Boccara, Guillaume. Los vencedores. Historia del pueblo mapuche en la época colonial. Santiago: Línea Editorial IIAM / Universidad Católica del Norte, 2007. 
Carrillo Cázares, Alberto. El debate sobre la guerra chichimeca, 1531-1585. Derecho y política en la Nueva España. 2 Tomos. México: El Colegio de Michoacán / El Colegio de San Luis, 2000.

Cramaussel, Chantal. "De cómo los españoles clasificaban a los indios: naciones y encomiendas en la Nueva Vizcaya central". Nómadas y sedentarios en el norte de México. Homenaje a Beatriz Braniff. Eds. Marie-Arite Hers y otros. México: Universidad Nacional Autónoma de México, Instituto de Investigaciones Antropológicas, Instituto de Investigaciones Históricas, Instituto de Investigaciones Estéticas, 2000.

Cubillos, Julio César. “Apuntes para el estudio de la cultura pijao”. Boletín de Arqueología 2.1 (1946): 47-81.

Doucet, Gastón Gabriel. "Sobre cautivos de guerra y esclavos indios en el Tucumán. Notas en torno a un fichero documental salteño del siglo XVIII”. Revista de Historia del Derecho 16 (1988): 59-152.

Friede, Juan. Los Andakí, 1538-1947. Historia de la aculturación de una tribu selvática. México: Fondo de Cultura Económica, 1974.

Giudicelli, Christophe. "Encasillar la frontera. Clasificaciones coloniales y disciplinamiento del espacio en el área Diaguito-Calchaquí, siglos XVI- XVII". Anuario del IEHS 22 (2007): 161-211.

. “Identidades' rebeldes. Soberanía colonial y poder de clasificación: sobre la categoría calchaquí (Tucumán, Santa Fe, siglos XVI-XVII)”. América colonial. Denominaciones, clasificaciones e identidades. Eds. Alejandra Araya Espinoza y Jaime Valenzuela Márquez. Santiago: RiL Editores, 2010.

Lucena Salmoral, Manuel."Datos antropológicos sobre los Pijao”. Revista Colombiana de Antropología 12 (1963): 359-386. Doi: 10.22380/2539472X.1696. . Historia extensa de Colombia.Volumen 3. Tomo 2. Dir. Academia Colombiana de Historia. Bogotá: Ediciones Lerner, 1965.

Paredes, Cisneros, Santiago. "Lengua pijao como lengua franca en las gobernaciones de Popayán y Neiva, siglos XVI-XVII”. Fronteras de la Historia 23.1 (2018): 40-66. Doi: 10.22380/20274688.311.

Restall, Matthew y Felipe Fernández-Armesto. Los conquistadores: una breve introducción. Madrid: Alianza Editorial, 2013.

Schäfer, Ernesto. El Consejo Real y Supremo de las Indias. Su historia, organización y labor administrativa hasta la terminación de la Casa de Austria. Tomo 1. Madrid: Junta de Castilla y León / Marcial Pons, 2003.

Triana Antorveza, Adolfo. La colonización española del Tolima. Siglos XVI y XVII. Bogotá: Funcol / Cuadernos del Jaguar, 1992.

Tovar Zambrano, Bernardo. “Conquista española y resistencia indígena. Las provincias de Timaná, Neiva y La Plata durante el siglo XVI”. Historia General del Huila. Tomo 1. Eds. Bernardo Tovar Zambrano, Guillermo González Otálora y Gabriel Castro Rouillé. Neiva: Instituto Huilense de Historia / Fondo de Autores Huilenses / Gobernación del Departamento del Huila / Academia Huilense de Historia, 1995. 
Valenzuela, Márquez, Jaime. "Del Biobío al Magdalena: para una historia conectada de experiencia militares y fronteras imperiales. Domingo de Erazo (1592-1617)". Trascendiendo fronteras. Circulaciones y espacialidades en torno al mundo americano. Eds. Fernando Purcell y Ricardo Arias Trujillo. Bogotá: Universidad de los Andes / Pontificia Universidad Católica de Chile, 2020.

Villamarín, Juan y Judith Villamarín. "Native Colombia: Contact, Conquest and Colonial Populations". Revista de Indias 63.227 (2003): 105-134. Doi: 10.3989/revindias.2003.i227.554. 